\title{
TRUTHMAKER REALISM:
}

\section{RESPONSE TO GREGORY}

\author{
Barry Smith \\ Preprint of paper to appear in Australasian Journal of Philosophy
}

\section{Truthmakers, Necessitation and Relevance}

If we want to give an account of the relation between those truths which have truthmakers and those portions of reality which make them true, a good place to start is with the notion of necessitation, which can be defined thus:

$x$ necessitates $p$ if and only if: $x$ exists and (that $x$ exists entails that $p$ ).

It is then tempting to embrace a simple definition of truthmaking along the following lines [4]:

\section{(A) $\quad x$ makes $p$ true if and only if: $x$ necessitates $p$.}

This definition is, unfortunately, subject to two sorts of difficulties, which we can refer to as Restall's refrigerator and John's funeral. The first consists in the fact that the view of truthmakers as necessitators implies that every contingently existing entity is a truthmaker for every necessary truth: Restall's refrigerator, in particular, is a truthmaker for ' $1+1=2$ ' [5]. The second consists in the fact that, if a portion of reality is a necessitator for some contingent truth $p$, then by the transitivity of entailment it is a necessitator also for all those contingent truths which are entailed by $p$. John's funeral, in particular, is a truthmaker for 'John is dead'.

To subvert these difficulties we need to find a way to block the transitivity of entailments, effectively by strengthening the definiens in (A) by imposing some factor of relevance beween $x$ and $p$. In my paper "Truthmaker Realism" I attempt to show how this needed blocking factor can be formulated exclusively in terms 
of mereology and classical entailment via the notion of projection (the dual of necessitation), defined as follows:

$x$ is projected by $p$ if and only if: $p$ and ( $p$ entails that $x$ exists).

I define the 'total projection' of $p$ as the sum of all those entities projected by $p$ and I then propose a definition of the truthmaker relation itself along the following lines:

(B) $\quad x$ makes $p$ true if and only if: $x$ necessitates that $x$ is part of the total projection of $p$.

I show that this definition captures the idea that $p$, if it is to be made true by $x$, must be about $x$. Goldbach's conjecture is not about Restall's refrigerator because Restall's refrigerator is not a part of that in the world upon which Goldbach's conjecture is projected. There are possible worlds in which Goldbach's conjecture is true but Restall's refrigerator does not exist. And likewise: there are possible worlds in which 'John is dead' is true, but the poor chap never had a funeral.

\section{No Truthbearers in Empty Worlds}

It is the thesis of Gregory [2] that this attempt to prune the abundance of malignant necessitators fails, and he takes it to follow from his arguments that any attempt to define truthmaking in terms of mereology and classical entailment must likewise fail.

He starts out from my statement to the effect that:

(C) Every contingent judgment entails the existence of something [6, p. 282].

He then provides an argument designed to show that (B) collapses onto (A) in the presence of $(\mathrm{C})$, and thus that the theory advanced in "Truthmaker Realism" avoids neither of the two difficulties mentioned.

The crucial step in this argument is Gregory's assertion to the effect that it 
follows from $(\mathrm{C})$ that

(D) 'there are no solid gold spheres with a diameter of $10^{10}$ miles' entails that something exists.

We can see what has gone wrong here if we reflect that (C) grows out of reflections, not on the issue of truthmakers at all, but rather on the nature of truthbearers. It reflects what is tentatively advanced in [6] as the favoured candidates for performing the truthbearing job, namely judgments (episodic judging acts). When this background is taken into account, then we see that (C) yields (D) only if the portion of the latter that is set in quotation marks is taken as carrying ontological commitment to a judgment in this token sense. Then, however, (D) itself is about a certain judgment and is thus true only in non-empty worlds. Gregory's argument for the collapse of (B) onto (A) accordingly itself collapses.

He is on the other hand right to put the finger on $(C)$ in its original formulation as a weak point in the argument of "Truthmaker Realism". It clearly needs a more careful formulation along the lines of:

(E) that an episodic act of judging (whether true or false, necessary or contingent) occurs entails that something (namely: this act of judging itself) exists,

which expresses merely the thesis that truthbearers are token judgments; that there are no truthbearers in empty worlds. We can see matters more clearly, perhaps, if we understand entailment in Kearns' truth-conditional sense [3, p. 329], according to which $p$ entails $q$ if and only if there is no way to satisfy the truth-conditions of $p$ without satisfying those of $q$. An episodic judgment need not truth-conditionally entail that something exists, since the truth-conditions of a judgment are satisfied (or not) independently of whether the judgment is ever made.

(E) itself, however, still obtains even when entailment is taken in the sense defined by Kearns. Moreover, the class of contingently true judgments can still, 
even in the presence of (E), be divided into two classes, viz.: those which have truthmakers and those which are true even though they lack truthmakers. The fact that there are judgments in the latter class (for example: 'there are no solid gold spheres with a diameter of $10^{10}$ miles') tells us that the position of truthmaker maximalism is not sustainable. Armstrong [1] and other defenders of this position hold that truth itself is to be defined in terms of the truthmaker relation (to be true is just: to be made true by some entity). Truthmaker realists, in contrast, insist that the relation between truth and truthmaking is more involved. Specifically, the truth of a judgment which has no truthmaker must be accounted for indirectly, for example by showing that the judgment in question is entailed by some other judgment for which a truthmaker can be isolated. The truth of certain existentially quantified statements, it turns out, has to be accounted for in this way. While Harvey the rabbit is not a truthmaker for 'there are rabbits' (contrary to what is stated at [6, p. 282]), the latter is true because it is entailed by 'Harvey is a rabbit', and for the latter judgment Harvey is indeed able to perform the truthmaking role.

\section{Gregory's Last Stand}

In the final portion of his paper Gregory argues that the theory of truthmaking advanced in [6] can still be shown to collapse even without appeal to (C). Recall that the role of the machinery of projection is to block those malignant necessitators which, given the transitivity of entailment, would otherwise count as truthmakers. Gregory thinks he can slingshot his way round this blockade by means of an argument involving disjunctive predicates. His argument does indeed show that the statement in "Truthmaker Realism" to the effect that

(F) [the total projection of a judgment $p$ includes among its parts] not only all those motley substances and tropes designated rigidly via $p$, but also all the mereological fusions of predicates whose satisfaction $p$ entails. ([6], $\mathrm{p}$. 282)

is erroneous. The predicate 'is a death or is identical to John's funeral' is a counterexample to this principle for the judgment $p$ expressed by 'John is dead'. 
Like (C), however, (F) belongs to informal commentary and not to the formal machinery of "Truthmaker Realism". When we examine the latter, then we see that Gregory's second argument does not go through. This is because it relies on a definition of total projection modeled on (F) ([2], p. 423), which inspection reveals to be markedly different from the definition advanced in the theory he is criticizing.

Gregory's second argument for collapse itself accordingly collapses, and so also does his pessimistic conclusion as to the viability of a conception of truthmakers along the lines defended in "Truthmaker Realism".

University at Buffalo

\section{REFERENCES}

[1] Armstrong, David M. 1997 A World of States of Affairs , Cambridge: Cambridge University Press.

[2] Gregory, Dominic 2001 "Smith on Truthmakers", Australasian Journal of Philosophy, 79 (3), 442-427.

[3] Kearns, John 1997 "Propositional Logic of Supposition and Assertion", Notre Dame Journal of Formal Logic, 38, 325-349.

[4] Mulligan, Kevin, Simons, Peter M. and Smith, Barry 1984 "Truth-Makers", Philosophy and Phenomenological Research, 44 287-321.

[5] Restall, Greg 1996 "Truthmakers, Entailment and Necessity", Australasian Journal of Philosophy, 72, 331-340.

[6] Smith, Barry 1999 "Truthmaker Realism", Australasian Journal of Philosophy, 77 (3), 1999, 274-291. 